\title{
Resorcinol Hydroxylase of Azoarcus anaerobius: Molybdenum Dependence, Activity, and Heterologous Expression
}

\author{
Paula I. Darley ${ }^{1,2} \cdot$ Jutta Hellstern ${ }^{1,3} \cdot$ Bernhard Schink $^{1} \cdot$ Bodo Philipp $^{1,4}$
}

\begin{abstract}
The obligately anaerobic, denitrifying bacterium Azoarcus anaerobius strain LuFRes1 grows with resorcinol (1,3-dihydroxybenzene) as sole carbon and energy source. Resorcinol is oxidized to hydroxyhydroquinone (1,2,4-trihydroxybenzene) by resorcinol hydroxylase $(\mathrm{RH})$, an inducible membrane-bound enzyme. Sequence comparison places resorcinol hydroxylase into the group of anaerobic molybdopterin oxidoreductases and dimethyl sulfoxide reductase-like enzymes. In the large subunit, a molybdopterin-binding domain was predicted, and the small subunit most likely contains two [4Fe- $4 \mathrm{~S}]$ centers. Growth of molybdate-starved cells was inhibited by tungstate, and in vitro resorcinol hydroxylase activity was inhibited by arsenite and selenite that are known to inhibit molybdenum-containing enzymes. The two genes encoding resorcinol hydroxylase could be expressed in Escherichia coli but the products remained in inclusion bodies. All attempts to purify $\mathrm{RH}$ from A. anaerobius or to produce soluble, active RH in E. coli failed. Nevertheless, $\mathrm{RH}$ was produced as a C-terminally Strep-tagged protein from plasmid pSKM1 in Thauera aromatica AR1 transconjugants carrying a transposon insertion in the coding gene for the large $(\Delta r h L)$ or the small subunit $(\Delta r h S)$ of $\mathrm{RH}$ from cosmid $\mathrm{R}^{+}$. RH in the membrane fraction of wild-type transconjugant T. aromatica AR1/R+ showed a specific activity of $80 \mathrm{mU} \mathrm{mg}^{-1}$, and the specific activity of $\mathrm{RH}$ in the membranes of the complemented mutants was in the same range ( $\left.80-95 \mathrm{mU} \mathrm{mg}^{-1}\right)$. We conclude that RH of $A$. anaerobius is a membrane-bound molybdoenzyme consisting of two subunits which might require a further loosely bound subunit as membrane anchor.
\end{abstract}

\section{Introduction}

Bacteria degrade aromatic compounds under oxic and anoxic conditions. In aerobic degradation of aromatics, molecular oxygen acts as a co-substrate in substrate activation and ring fission [1]. In the absence of oxygen, different strategies are used for degradation of aromatics. First, the broad variety of aromatic compounds is transformed into few central intermediates, namely benzoyl-CoA, hydroxyhydroquinone, phloroglucinol, and resorcinol, which are subsequently

\section{Bodo Philipp}

bodo.philipp@uni-muenster.de

1 University of Konstanz, Fachbereich Biologie, 78457 Constance, Germany

2 Present Address: Cambivac Ltd, Cambridge CB22 3AT, UK

3 Present Address: Novartis Pharma AG, Lichtstrasse 35, 4056 Basel, Switzerland

4 Present Address: Institute for Molecular Microbiology and Biotechnology, University of Münster, Corrensstr. 3, 48149 Münster, Germany de-aromatized and further degraded [2-5]. Most anaerobic bacteria reduce the aromatic ring of the central intermediates before ring fission takes place by benzoyl-CoA reductases which are the most common enzymes involved in ring reduction. However, Azoarcus anaerobius and Thauera aromatica AR1, two nitrate-reducing bacteria, attack resorcinol or $\alpha$-resorcylate (3,5-dihydroxybenzoate) anaerobically by an oxidative rather than a reductive reaction. Azoarcus anaerobius hydroxylates resorcinol to hydroxyhydroquinone (1,2,4-trihydroxybenzene, HHQ) [6], and T. aromatica AR1 transforms $\alpha$-resorcylate as well by hydroxylation, followed by decarboxylation to HHQ [7]. HHQ is oxidized by a membrane-bound enzyme to hydroxybenzoquinone (2-hydroxy1,4-benzoquinone, HBQ), a non-aromatic intermediate which is prone to ring fission, both in A. anaerobius and in T. aromatica AR1 [8].

The oxidative pathway involving HHQ is apparently widespread in anoxic habitats [9] and its regulation has been investigated in A. anaerobius LuFRes 1 and $T$. aromatica AR1 $[10,11]$. In vitro studies with $A$. anaerobius strain LuFRes1 demonstrated that resorcinol hydroxylase (RH) 
activity is membrane-associated and uses nitrate or potassium ferricyanide as electron acceptor [6]. A genomic fragment of A. anaerobius was isolated that is located on cosmid $\mathrm{R}^{+}$and enables the $T$. aromatica strains $\mathrm{AR} 1$ and $\mathrm{K} 172$ to grow with resorcinol. By heterologous expression of mutagenized cosmids in both $T$. aromatica strains, we identified the genes encoding resorcinol hydroxylase, HHQ dehydrogenase, and putative enzymes for ring fission of HBQ [12]. Furthermore, genes involved in $\alpha$-resorcylate degradation have been identified in $T$. aromatica AR1 [13]. Mutants defective in the genes $d b h L$ and $d b h S$ are not able to grow with $\alpha$-resorcylate and are also deficient in $\alpha$-resorcylate hydroxylase activity. Anaerobic hydroxylation reactions are often catalyzed by molybdenum-containing enzymes [14]. The genes encoding resorcinol hydroxylase as well as $d b h L S$ from strain AR1 were found to be homologous to the genes for phloroglucinol-pyrogallol transhydroxylase of Pelobacter acidigallici, a well-characterized molybdoenzyme [15]. The goal of the present study was to investigate in vivo and in vitro whether resorcinol hydroxylase is a molybdenumcontaining enzyme.

\section{Materials and Methods}

\section{Materials}

All chemicals and biochemicals were purchased from Fluka, Merck, Serva, Sigma-Aldrich or Biozym and were of the highest quality available. Enzymes used for cloning and other materials used for molecular biology techniques were obtained from MBI Fermentas, Invitrogen, Stratagene, or Qiagen. PCR and sequencing primers were purchased from MWG. Custom sequencing was performed at GATC. Streptactin AP conjugate used for the western blots was purchased from IBA GmbH. Protein molecular mass marker was purchased from Bio-Rad and DNA size markers were from MBI Fermentas.

\section{Bacterial Strains, Vectors, and Culture Conditions}

Bacteria and vectors used in this work are summarized in Table 1. Unless stated otherwise, A. anaerobius strain

Table 1 Bacterial strains and vectors used in this study

\begin{tabular}{|c|c|c|}
\hline Strain or vectors & Relevant characteristics & Source or reference \\
\hline \multicolumn{3}{|l|}{ Strains } \\
\hline \multicolumn{3}{|l|}{ A. anaerobius } \\
\hline LuFRes1 (DSM12081) & Wild-type, Res $^{+}$ & [38] \\
\hline \multicolumn{3}{|l|}{ T. aromatica } \\
\hline AR1 (DSM11528) & Wild-type, Res ${ }^{-}, \mathrm{DHB}^{+}, \mathrm{HHQ}$ pathway ${ }^{+}$ & [7] \\
\hline \multicolumn{3}{|l|}{ E. coli } \\
\hline DH5 $\alpha$ & $\begin{array}{l}\left.\mathrm{F}^{-}, \varphi 80 \mathrm{~d} l a c Z \Delta \mathrm{M} 15, \Delta(\text { lacZYA-argF }) \mathrm{U1} 69, \text { deoR, recA1, endA1, hsdR17(rk-, mk }{ }^{+}\right) \text {, } \\
\text { phoA, supE44, } \lambda^{-} \text {, thi-1, gyrA96, relA1 }\end{array}$ & [16] \\
\hline HB101 & $\begin{array}{l}\text { supE } 44, \text { hsdS20 }\left(r_{\mathrm{B}}{ }^{-} m_{\mathrm{B}}{ }^{-}\right), \text {recA13, ara-14, proA2, galK2, rpsL20, xyl-5, mtl-1, leuB6, } \\
\text { thi-1, lacY1, }\end{array}$ & [16] \\
\hline BL21 (DE3) Codon Plus-RIL & 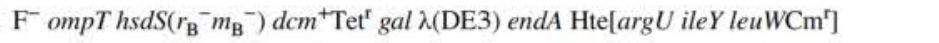 & Stratagene \\
\hline Rosetta (DE3)pLysS & $\mathrm{F}^{-}$omp $T h s d S_{\mathrm{B}}\left(\mathrm{r}_{\mathrm{B}}{ }^{-} \mathrm{m}_{\mathrm{B}}{ }^{-}\right)$gal dcm (DE.3) pLysSRARE2 $\left(\mathrm{Cm}^{\mathrm{r}}\right)$ & Novagen \\
\hline \multicolumn{3}{|l|}{ Plasmids } \\
\hline pRK600 & $\mathrm{Cm}^{\mathrm{r}}, \mathrm{ColE} 1, \mathrm{Tra}^{+}$ & [39] \\
\hline pASK-IBA3plus & $\mathrm{Ap}^{\mathrm{r}}, \mathrm{f} 1$, tet $\mathrm{A}$ promoter, tag fused at C-terminus, used for construction of $\mathrm{pPDI} 2$ & IBAGmbH \\
\hline pASK-IBA5plus & $A p^{r}, f 1, \operatorname{tet} \mathrm{A}$ promoter, tag fused at $\mathrm{N}$-terminus, used for construction of $\mathrm{pPD} 2$ & IBAGmbH \\
\hline pBBR-MCS5 & $\mathrm{Gm}^{\mathrm{r}}$, broad-host-range, used for construction of pSKM1 & {$[40]$} \\
\hline pPD2 & $\mathrm{Ap}^{\mathrm{r}}$, expression plasmid of $\mathrm{N}$-terminus tagged protein & This study \\
\hline pPID2 & $A p^{r}$, expression plasmid of C-terminus tagged protein & This study \\
\hline pSKM1 & $\begin{array}{l}\mathrm{Gm}^{\mathrm{r}} \text {, complementing plasmid harboring } r h L S \text { with Strep-tag at C-terminus of RhS } \\
\text { subunit }\end{array}$ & This study \\
\hline \multicolumn{3}{|l|}{ Cosmids } \\
\hline $\mathrm{R}^{+}$ & $\mathrm{Tc}^{\mathrm{r}}$, pLAFR3 containing a 29.9-kp resorcinol gene cluster of $A$. anaerobius & [12] \\
\hline $\mathrm{Mu} 21(\Delta r h L)$ & $\mathrm{Tc}^{\mathrm{r}}, \mathrm{Km}^{\mathrm{r}}, \mathrm{R}^{+} r h L:: \mathrm{TN}<\mathrm{KAN}-2>, r h L$ transposon mutant & [12] \\
\hline $\mathrm{Mu} 40(\Delta r h S)$ & $\mathrm{Tc}^{\mathrm{r}}, \mathrm{Km}^{\mathrm{r}}, \mathrm{R}^{+} r h S:: \mathrm{TN}<\mathrm{KAN}-2>, r h S$ transposon mutant & [12] \\
\hline
\end{tabular}

$\operatorname{Res}^{+}$growth on resorcinol, $\mathrm{Res}^{-}$no growth on resorcinol, $\mathrm{DHB}^{+}$growth on 3,5-dihydroxybenzoate, $\mathrm{DHB}^{-}$no growth on 3,5-dihydroxybenzoate, $H H Q$ pathway ${ }^{+}$possess HHQ pathway, $\mathrm{Km}^{r}$ kanamycin resistant, $\mathrm{Cm}^{r}$ chloramphenicol resistant, $\mathrm{Ap}^{r}$ ampicillin resistant, $\mathrm{Gm}^{r}$ gentamicin resistant 
LuFRes1 (DSM12081) and T. aromatica strain AR1 (DSM 11528 ) were cultured under denitrifying conditions in nonreduced mineral medium with resorcinol $(2 \mathrm{mM})$ as the sole source of carbon and energy as described previously [12]. $\mathrm{N}_{2} \mathrm{O}$ was added to cultures to a final concentration of $10 \%$ with a glass syringe through a hydrophobic sterile filter. Growth was measured as optical density at $578 \mathrm{~nm}$ $\left(\mathrm{OD}_{578}\right)$ either directly in test tubes with a Bausch and Lomb Spectronic 70 spectrophotometer or in $1 \mathrm{~cm}$ cuvettes with a Hitachi 100-40 spectrophotometer. Molybdenum-free medium was prepared by omitting the selenite-tungstate solution and the molybdate in the SL 10 solution. For these experiments, all glassware was pre-incubated overnight in $25 \% \mathrm{HCl}$, washed four times with pure Milli-Q water, incubated for more than $6 \mathrm{~h}$ in $4 \mathrm{~N} \mathrm{NaOH}$, and washed again 4 times with pure Milli- $\mathrm{Q}$ water.

Thauera aromatica AR1 transconjugants carrying the Mu_40 ( $\Delta r h S)$ or Mu_21 ( $\Delta r h L)$ cosmid [12] with or without the $\mathrm{pSKM} 1$ vector were grown under the same conditions in the presence of kanamycin $\left(50 \mu \mathrm{g} \mathrm{ml}^{-1}\right)$ with or without gentamicin $\left(10 \mu \mathrm{g} \mathrm{ml}^{-1}\right)$, respectively. For biochemical studies, all strains were cultured in 11 infusion bottles and harvested at an $\mathrm{OD}_{578}$ of $0.3-0.4$. Cultures were supplemented with the carbon source and nitrate from $0.5 \mathrm{M}$ sterile stock solutions. To study functional complementation of the $T$. aromatica AR1 carrying Mu_40 or Mu_21 cosmids, $100 \mathrm{ml}$ serum bottles containing $50 \mathrm{ml}$ anoxic mineral medium supplemented with resorcinol $(2 \mathrm{mM})$, nitrate $(8 \mathrm{mM})$, kanamycin $\left(50 \mu \mathrm{g} \mathrm{ml}^{-1}\right)$, and gentamicin $\left(10 \mu \mathrm{g} \mathrm{ml}^{-1}\right)$ were inoculated with $1 \%$ pre-culture. Escherichia coli $\mathrm{HB} 101$ (pRK600) was used as a helper strain and DH5 $\alpha$ harboring Mu_40 or $\mathrm{Mu} \_21$ cosmids or the pSKM1 vector, were used as donor strains in triparental matings as described previously [12]. All E. coli strains were grown aerobically at $37^{\circ} \mathrm{C}$ in Luria-Bertani, LB [16] or Standard I medium from Merck. Antibiotics were used at the following concentrations: tetracycline, $20 \mu \mathrm{g} \mathrm{ml}^{-1}$; chloramphenicol, $30 \mu \mathrm{g} \mathrm{ml}^{-1}$; carbenicillin, $50 \mu \mathrm{g} \mathrm{ml}^{-1}$; kanamycin, $50 \mu \mathrm{g} \mathrm{ml}^{-1}$; gentamicin, $10 \mu \mathrm{g} \mathrm{ml}^{-1}$.

\section{Construction of Expression and Complementation Plasmids}

Routine manipulation of plasmid DNA, PCR, and construction of recombinant plasmids were performed as previously described [16]. The individual cloning steps were carried out in E. coli $\mathrm{DH} 5 \alpha$.

\section{Construction of Expression Plasmids}

Genomic DNA of A. anaerobius strain LuFRes1 was isolated with Puregene DNA Purification Kit (Qiagen) and used as a template for amplification of resorcinol hydroxylase genes by PCR. To minimize PCR errors a Hi-Fidelity DNA polymerase (Phusion, NEB) was employed. For cloning $r h \mathrm{LS}$ genes in pASK-IBA5plus expression plasmid the following primers were used: 5 '-ATGGTACGTCTCAGCGCC ATGGTCATTGGCCGCGACGAG-3' (forward) and 5'-ATG GTACGTCTCATATCACGCCTGCGCGCGCTGCTGG-3' (reverse) and for cloning in pASK-IBA3plus expression plasmid 5'-AGAATTTTGGTACCATGGTCATTGGCCGC GACGAGCTG-3' (forward) and 5'-AGGCCTCGAGAGA CGCCTGCGCGCGCTGCTG-3' (reverse) oligonucleotides were used. The cleavage sites for the restriction enzymes in the above primers are underlined. The amplified fragments were either digested with Esp3I and inserted into the Eco31I site of pASK-IBA5plus or digested with both $K p n I$ and $X h o I$ and ligated into the $K p n I-X h o I$ site of pASK-IBA3plus. The first approach generated the expression plasmid pPD2 while the latter yielded pPID2. Both plasmids were double-strand sequenced by a company (GATC, Constance, Germany).

\section{Construction of Complementation Plasmid}

A fragment carrying both resorcinol hydroxylase genes and the Strep-tag was obtained from plasmid pPID2 digested with both KpnI and HindIII and ligated into the KpnI-Hin$d \mathrm{III}$ site of the broad host-range vector pBBR-MCS5; the constructed plasmid was designated pSKMI.

\section{Resorcinol Hydroxylase Gene Expression in E. coli}

The $E$. coli Rosetta (DE3)pLysS strain was used to transform the expression plasmids pPD2 and pPID2. The growth conditions (media, temperature, oxygen, molybdate) and the concentration of the inducer were varied in order to establish optimal conditions for the production of soluble proteins. Cells were grown aerobically at $30-37^{\circ} \mathrm{C}$ and induced at $\mathrm{OD}_{578}=0.3-0.5$ with anhydrotetracycline $\left(200 \mu \mathrm{g} \mathrm{l}^{-1}\right)$ for further $3 \mathrm{~h}$.

\section{Testing for Complementation}

Plasmid pSKM1 was mated into T. aromatica AR1 transconjugants carrying Mu_21 $(\Delta r h L)$ or Mu_40 $(\Delta r h S)$ cosmid via triparental-mating as described before [12] and selected by growth under denitrifying conditions in non-reduced minimal medium with resorcinol and 3,5-dihydroxybenzoate ( $2 \mathrm{mM}$ each) as the sole carbon and energy source plus nitrate $(16 \mathrm{mM})$, kanamycin $\left(50 \mu \mathrm{g} \mathrm{ml}^{-1}\right)$ and gentamicin $\left(10 \mu \mathrm{g} \mathrm{ml}^{-1}\right)$. The transconjugants were analyzed for colony shape and motility, and 16S rDNA gene sequencing confirmed that the transconjugants were indeed $T$. aromatica AR1. After three transfers with both carbon sources, the resulting transconjugant strains were tested to determine if the subclone complemented the mutations by growing the 
cultures in the presence of kanamycin and gentamicin with resorcinol. The ability of the transconjugants to grow with resorcinol was confirmed by substrate depletion analysis, and immunoblotting analysis was employed to confirm $\mathrm{RH}$ expression in the complemented mutants. Growth and substrate depletion were analyzed as described previously [12].

\section{Preparation of Cell-Free Extracts and Detection of Resorcinol Hydroxylase Activity}

Cell-free extracts for biochemical tests were prepared anoxically as described before [12]. Resorcinol hydroxylase activity was determined anoxically at $30{ }^{\circ} \mathrm{C}$ in a total volume of $1 \mathrm{ml}$ containing $50 \mathrm{mM}$ potassium phosphate buffer, $\mathrm{pH}$ $7.0,1 \mathrm{mM} \mathrm{K}_{3} \mathrm{Fe}(\mathrm{CN})_{6}$, and 0.5 to $1.5 \mathrm{mg}$ total protein. The reaction was started by addition of $1 \mathrm{mM}$ resorcinol, and the reduction of $\mathrm{K}_{3} \mathrm{Fe}(\mathrm{CN})_{6}$ was monitored in a Hitachi $100-40$ spectrophotometer at $420 \mathrm{~nm}\left(\varepsilon=0.9 \mathrm{mM}^{-1} \mathrm{~cm}^{-1}\right)$. One unit of activity is defined to catalyze the reduction of $1 \mu \mathrm{mol}$ of $\mathrm{K}_{3} \mathrm{Fe}(\mathrm{CN})_{6} \mathrm{~min}^{-1}$ at $30^{\circ} \mathrm{C}$.

\section{Purification of Resorcinol Hydroxylase}

All purification steps were performed in an anoxic chamber (Coy Laboratories) in a $\mathrm{N}_{2} / \mathrm{H}_{2}(95 \% / 5 \%)$ atmosphere at $15-20{ }^{\circ} \mathrm{C}$. Resorcinol hydroxylase $(\mathrm{RH})$ was purified from anaerobically grown cells of $T$. aromatica AR1/Mu_40 (pSKM1) transconjugant. The cell pellet $(1 \mathrm{~g})$ was washed with buffer $\mathrm{A}(100 \mathrm{mM}$ potassium phosphate buffer, $\mathrm{pH}$ 7.6) and resuspended in $3 \mathrm{ml}$ buffer $\mathrm{B}(100 \mathrm{mM}$ potassium phosphate buffer, $\mathrm{pH} 7.6$, with $150 \mathrm{mM} \mathrm{NaCl}$ ). Cell-free extract was prepared as described previously [12]. Membranes were resuspended and solubilized in $3 \mathrm{ml}$ buffer B supplemented with $3 \%(\mathrm{w} / \mathrm{v})$ Triton X-100 and incubated for $2 \mathrm{~h}$ on ice. Cell debris was removed by ultracentrifugation $(100,000 \times g$, $1 \mathrm{~h}$ ) and the clear supernatant was diluted to a final volume of $9 \mathrm{ml}$ with buffer B and applied to a Strep-Tactin Superflow column $(1 \mathrm{ml})$ equilibrated with buffer $\mathrm{C}$ [buffer B supplemented with $1 \%(\mathrm{w} / \mathrm{v})$ Triton X-100]. Non-bound protein was washed off with buffer B prior to elution of RH with d-desthiobiotin ( $2.5 \mathrm{mM}$ ) in buffer B. The enzyme (fraction 3 and 4) was concentrated in $500 \mu \mathrm{l}$ Vivaspin centrifugation devices with a $30 \mathrm{kDa}$ cut-off.

\section{Protein Determination}

Protein concentrations were determined according to Bradford [17] with bovine serum albumin as standard.

\section{High-Performance-Liquid-Chromatography (HPLC)}

HPLC analyses were used as described previously for quantifying resorcinol [6] and nitrate/nitrite [12].

\section{Electrophoresis and Western Blotting}

SDS-PAGE was performed in a vertical electrophoresis device (Mini-Protean II, Germany) after Laemmli [18]. Gels consisted of a $5 \%$ stacking gel and a $10 \%$ or $12 \%$ resolving gel and were run at $120 \mathrm{mV}$ voltage. Protein samples were pre-treated with SDS-loading buffer $(50 \mathrm{mM}, 2 \%$ SDS, $0.1 \%$ bromophenol blue, $10 \%$ glycerol, $100 \mathrm{mM} \mathrm{DTT}$ ) for $3 \mathrm{~min}$ at $100{ }^{\circ} \mathrm{C}$, and $6 \mu \mathrm{g}$ protein was loaded per lane. Gels were stained with Coomassie Brilliant Blue R250 (0.1\%) for $4 \mathrm{~h}$ and de-stained (10\% glacial acetic acid, $40 \%$ methanol) for another 3-4 h. Digital pictures were taken immediately after de-staining. For western blotting, protein samples were subjected to SDS-PAGE and transferred ( $400 \mathrm{~mA}, 90 \mathrm{~min}$ ) onto a nitrocellulose membrane $(0.2 \mu \mathrm{m})$. Resorcinol hydroxylase immunoblot analysis was performed using Strep-tactin alkaline phosphatase conjugate, and the signals were detected with NTB and BCIP according to the supplier's recommendation.

\section{Sequence Analysis}

Nucleotide and amino acid sequences were analyzed using tools provided by the National Center for Biotechnology Information (https://www.ncbi.nlm.nih.gov/blast/), and the ExPASy molecular biology server (https://www.expas y.ch/). Transmembrane helices in proteins were predicted using TMHMM server 2.0 (https://www.cbs.dtu.dk/services/ TMHMM/).

\section{Sequence Accession Numbers}

The amino acid sequences for $\mathrm{RhS}$ and $\mathrm{RhL}$ were deposited in the NCBI (GenBank) under the accession numbers ABK58619 and ABK58620, respectively.

\section{Results and Discussion}

\section{Analysis of the Amino Acid Sequences of the Two Subunits of Resorcinol Hydroxylase}

Based on genetic evidence, the $r h L S$ genes of the $A$. anaerobius genome have been suggested to encode RH [12]. According to the nucleotide sequence, the polypeptides encoded by the $r h L S$ genes representing the large and the small subunits of the hydroxylase consist of 915 and 298 amino acids and have predicted molecular masses of 102.7 and $33.2 \mathrm{kDa}$, respectively. The $r h L$ and $r h S$ genes are separated by a 49 nucleotide non-coding DNA sequence. Data Bank analysis and alignment studies for RhS and RhL revealed identities of $49 \%$ and $52 \%$ and similarities of $68 \%$ and $66 \%$, respectively, to the functionally analyzed small 
and large subunits of $P$. acidigallici pyrogallol-phloroglucinol transhydroxylase (aTH). Sequence analysis of RhL showed that RH, as well as pyrogallol-phloroglucinol transhydroxylase, belongs to the DMSO reductase (DMSOR) family (Fig. 1a). Enzymes within the DMSOR family are characterized by the presence of one molybdenum atom and two molecules of molybdopterin guanosine dinucleotide (MGD) and share a molybdenum-containing large subunit, such as DMSO reductase $[19,20]$, formate dehydrogenase $[21,22]$, and dissimilatory nitrate reductase [23], but may also have one or two additional small subunits as found in pyrogallol-phloroglucinol transhydroxylase [15] or formate dehydrogenase-N [22]. Crystal structures have been solved for DMSO reductase [20] and pyrogallol-phloroglucinol transhydroxylase [15]. Of the 30 amino acids shown to contact the molybdenum cofactor (MoCo) in DMSO reductase and in the alpha subunit of pyrogallol-phloroglucinol transhydroxylase, 12 and 24 residues, respectively, are identical in the large subunit of resorcinol hydroxylase, indicating that the MoCo should be bound exclusively in RhL (data not shown). In pyrogallol-phloroglucinol transhydroxylase, Ser 175 is the molybdenum-coordinating residue, while Tyr560 has been proposed not to be involved in the catalytic mechanism but to be an active site "protector" since its side chain can adopt two different conformations. When a substrate or an inhibitor enters the channel to the active site, a recognition process takes place allowing tyrosine 560 to change its conformation in order to open or lock the access to the molybdenum [15]. Interestingly, Ser 196 of RhL aligns to Ser175 of aTH, and Tyr572 aligns to Tyr560 (Fig. 1a).

An amino acid sequence alignment of the deduced $A$. anaerobius rhS gene product and the small subunit of pyrogallol-phloroglucinol transhydroxylase of $P$. acidigallici is shown in Fig. 1b. Eight out of eleven cysteines present in $A$. anaerobius $\mathrm{RhS}$ aligned to the eight cysteines of the $P$. acidigallici protein previously shown to be involved in iron-sulfur cluster coordination [15]; the same cysteines also aligned with eight cysteines of the beta subunit of dimethylsulfide dehydrogenase of Rhodovulum sulfidophilum. The beta subunit of dimethylsulfide dehydrogenase, an iron-sulfur cluster enzyme, is predicted to be involved in electron transfer during phototrophic growth with dimethylsulfide. These in silico findings strongly suggest the presence of a molybdenum cofactor in $\mathrm{RhL}$ and at least two $4 \mathrm{Fe}-4 \mathrm{~S}$ clusters in $\mathrm{RhS}$.

Although resorcinol hydroxylase activity is localized in the membrane fraction, the sequences do not show any indications for a transmembrane domain.

\section{Effect of Molybdate on A. anaerobius Growth and Resorcinol Hydroxylase Activity}

Molybdenum cofactor-containing enzymes catalyze the transfer of an oxygen atom derived from or incorporated into water, to or from a substrate in a two-electron redox reaction $[24,25]$. For supporting the sequence-based prediction of resorcinol hydroxylase being a molybdenumcontaining enzyme, physiological experiments with molybdenum-starved cells were performed. As A. anaerobius is a denitrifying bacterium, it will also have at least one further molybdenum-containing enzyme, i.e., nitrate reductase [26]. We therefore looked for the effect of molybdate on A. anaerobius resorcinol metabolism in vivo, and in vitro by assaying membrane fractions prepared from cells grown with resorcinol in the absence of molybdate for resorcinol hydroxylase activity.

Azoarcus anaerobius was cultivated in molybdate-free medium with resorcinol as carbon and energy source with either nitrate or $\mathrm{N}_{2} \mathrm{O}$ as electron acceptor for more than seven subsequent transfers ( $5 \%$ transfer each). Even after 10 transfers in medium without molybdate, the cells still grew and metabolized resorcinol (Fig. 2a), however, at much lower rate than in the presence of molybdenum (Fig. 2b). In addition, these cells accumulated nitrite indicating that its further reduction was somehow impeded. Although every effort was made to avoid exogenous introduction of molybdate, trace amounts present in the medium components, glass, and syringe needles used to inoculate and take samples from the cultures could presumably not be completely eliminated. Addition of the molybdate antagonist tungstate $(0.02 \mathrm{mM})$ inhibited growth with resorcinol completely (Fig. 3a, b). In cultures grown with nitrate, no nitrite was formed. The few bacterial cells visible were heavily deformed and immotile, and formed aggregates. Addition of molybdate $(0.02 \mathrm{mM})$ caused an increase in $\mathrm{OD}_{578}$ (Fig. 3a, b) and nitrite formation, and the cells returned to normal shape.

In similar experiments with acetate as growth substrate, growth with nitrate as electron acceptor was slightly retarded after addition of tungstate (Fig. 3c). Addition of molybdate had no influence on the final $\mathrm{OD}_{578}$. With nitrous oxide as electron acceptor, the final $\mathrm{OD}_{578}$ was not affected by addition of tungstate or molybdate (Fig. 3d). Interestingly, cells grown in minimal medium with resorcinol but lacking molybdate also formed large cell aggregates after 2 weeks of incubation without shaking. Cells grown with resorcinol in the presence of molybdate did not form such aggregates, even after 3 months of incubation without shaking.

Tungsten is known to be a molybdenum antagonist [26] due to its similar physical and chemical properties [27]. Growth inhibition of A. anaerobius by tungstate was observed only in cultures with resorcinol, independent of the used electron acceptor. Growth with acetate plus nitrate was slightly delayed, probably due to impairment of the nitrate reductase [26].

Specific activities of $\mathrm{RH}$ in membrane fractions prepared from A. anaerobius cells grown in the absence of molybdate were significantly lower $\left(7 \mathrm{mU} \mathrm{mg}^{-1}\right)$ than those from 
Fig. 1 Sequence alignments of $\mathrm{RH}$ subunits. Alignment was performed using the ClustalW program [41]; amino acids identical in all three sequences are shaded in red, and amino acids identical in at least two sequences are shaded in yellow. a Sequence alignment of RhL and members of the DMSO reductase family from P. acidigallici large subunit of pyrogallol-phloroglucinol transhydroxylase (aTH) and $R$. sphaeroides $\mathrm{DMSO} /$

TMAO-reductase (Dms).

Ser175 from alpha subunit of pyrogallol-phloroglucinol transhydroxylase is indicated with asterisk and Tyr 560 with a triangle. Aa A. anaerobius, Pa Pelobacter acidigallici, $R$ s Rhodobacter sphaeroides. b Sequence alignment of RhS and other iron-sulfur proteins: A. anaerobius small subunit of resorcinol hydroxylase (RhS), $P$. acidigallici beta subunit of pyrogallol-phloroglucinol transhydroxylase (bTH) and $R$. sulfidophilum dimethylsulfide dehydrogenase beta subunit (bDh). The cysteines shown to bind the first, second and third [4Fe-4S] in bTH are shaded light gray, green and cyan, respectively. Aa A. anaerobius, Pa Pelobacter acidigallici, Rs Rhodovulum sulfidophilum (Color figure online)
A

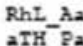

${ }_{\mathrm{Dm}}^{2 \mathrm{TH}} \mathrm{Rg}$

Rhi_ Aa

${ }_{2 H_{-}^{-}}^{-P 2}$

Dems $R$ s

RhI_A2

${ }_{2 T H} P_{2}$

$D=s$, $R$,

Rhi__Aa

${ }_{D m}^{2}-P_{2}^{-} P_{2}$

RhI_A2

aTH-P2

Dess $R$,

RhI_Aa

${ }_{D \rightarrow B}-P_{R}$

RhL_Aa

$2 \mathrm{TH}_{-}^{\mathrm{Pa}}$

Dms_Rs

RhI_Ad

$\mathrm{THH}_{-}^{-\mathrm{Pa}_{2}}$

$D=s_{-} R$,

RhL_Aa

${ }_{2} \mathrm{TH}_{-} \mathrm{Pa}$

Dms. R

Rht Aa

${ }_{2} \mathrm{TH}_{-}^{-} \mathrm{Pa}$

Dens_Rs

RhL_Aa

$\mathrm{ATH}_{-} \mathrm{Pa}_{2}$

Dems $R$ s

$\mathrm{RhL}$ Aa

aTH $P=$

$D_{n=5}{ }^{P}$,

RhI_Aa

$2 T T_{-}^{-} P_{2}$

RhL_Aa

$\mathrm{RhL}_{2} \mathrm{Aa}$
$\mathrm{THH}_{-} \mathrm{Pa}$

Dms. $R$ s

RhI_Aa

${ }^{2 T H}-P^{-} P_{2}$

RhI_Aa

${ }_{\mathrm{Dm}}^{2 \mathrm{TH}}-\mathrm{P}_{\mathrm{R}}$

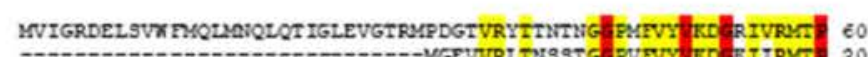

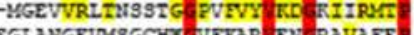

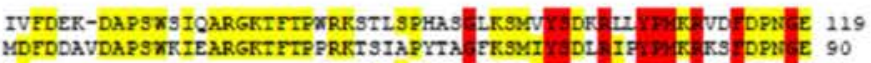

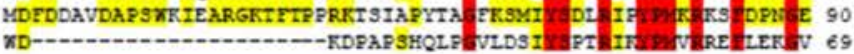

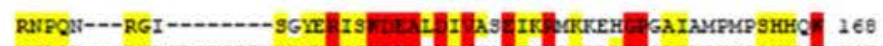

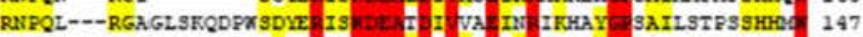

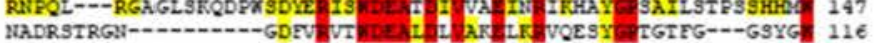

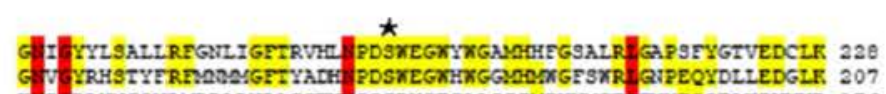

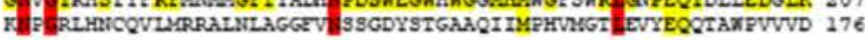

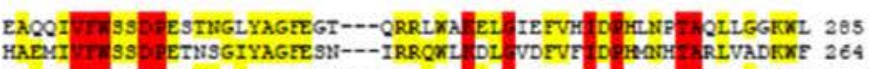

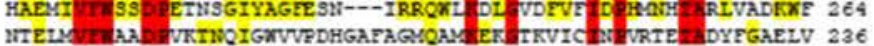

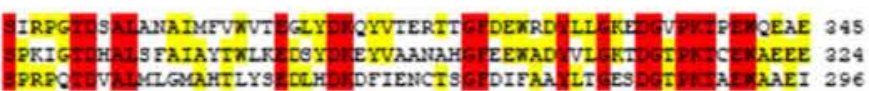

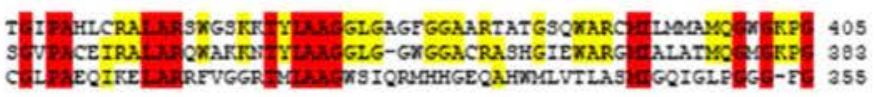

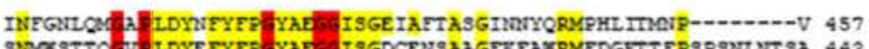

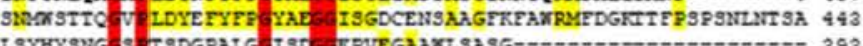
ISYYYSMG

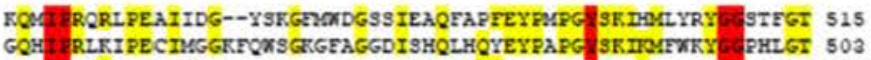

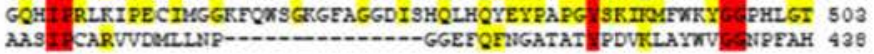

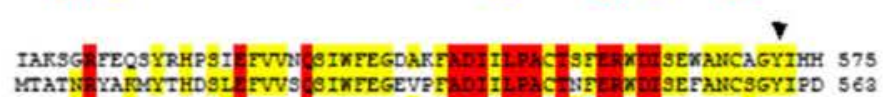

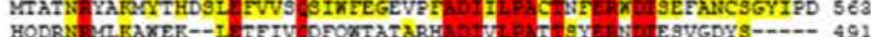

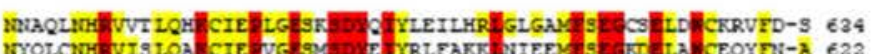

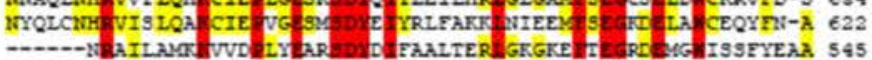

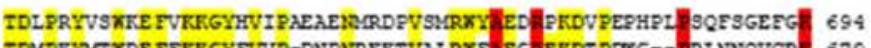

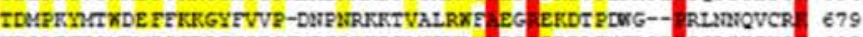

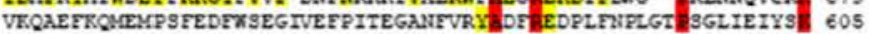

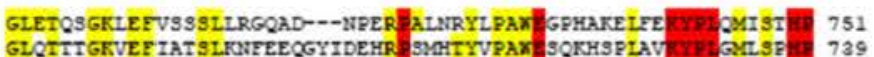

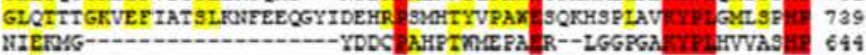

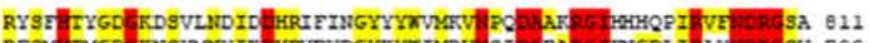

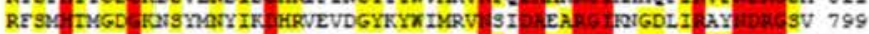

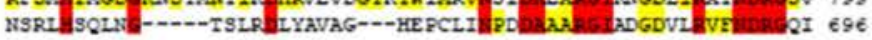

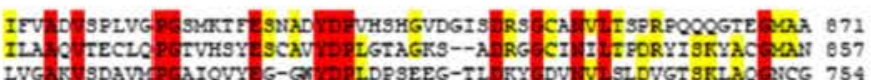
ASC VEEN PKI PPAGLKSHVOIRGMPPSIERPAASARAXANVRV 915

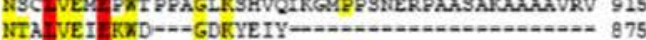
WTA VEI IKDDG-GDKYETY 
Fig. 1 (continued)
B

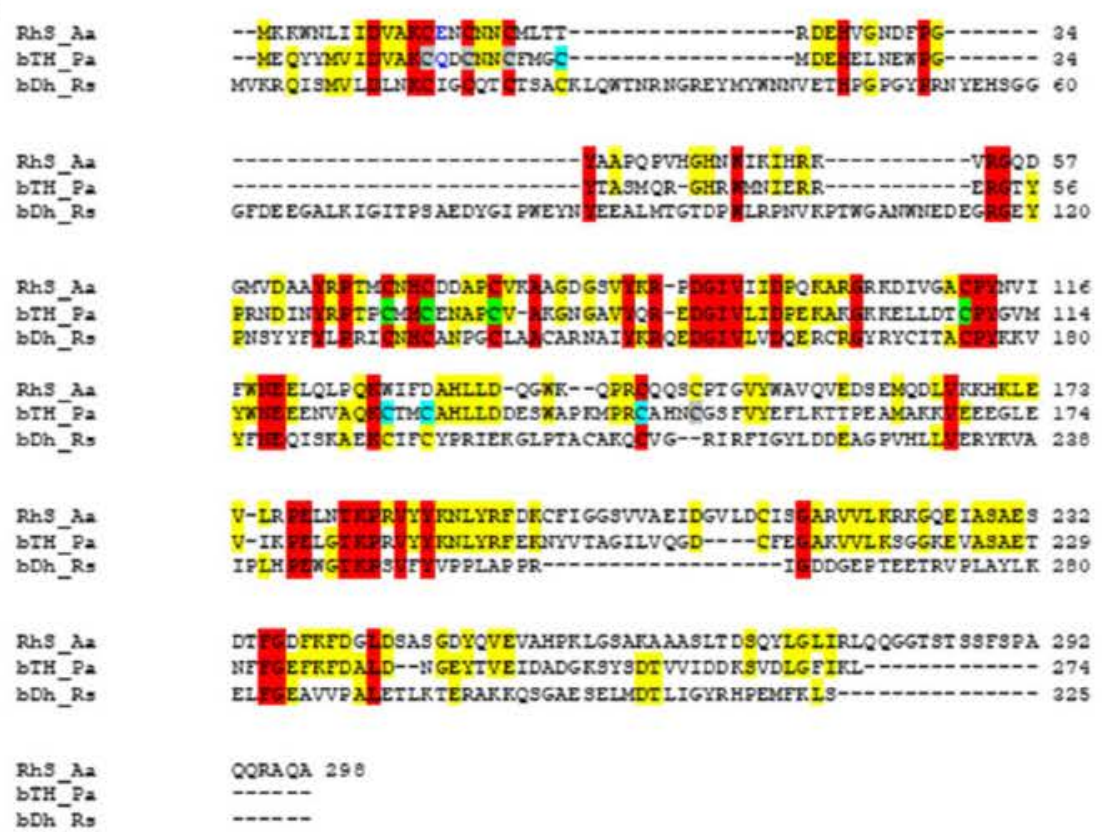

cells that had not been starved for molybdate $\left(95 \mathrm{mU} \mathrm{mg}^{-1}\right)$. While cyanide, a prominent inhibitor of molybdenum-containing enzymes [28], did not inhibit RH (results not shown), arsenite and selenite ( $1 \mathrm{mM}$ each) decreased the RH activity by 97 and $61 \%$, respectively. Both inhibitors can destabilize the molybdenum bonding inside the protein by forming a complex with the thiol groups of the molybdenum cofactor [30]. Taken together, these results clearly support the prediction of the sequence alignments that $A$. anaerobius resorcinol hydroxylase is a molybdenum-containing enzyme.

\section{Expression of Resorcinol Hydroxylase in E. coli}

Previously, it was reported that resorcinol hydroxylase activity could be measured in the A. anaerobius membrane fractions solubilized with $1 \%(w / v)$ CHAPS [6]. Since all attempts to purify this enzyme from solubilized $A$. anaerobius membranes failed, heterologous expression was chosen for purification and characterization of this enzyme. The genes $r h L S$ coding for the two subunits of $\mathrm{RH}$ were amplified as single fragments and ligated in pSK-IBA5plus and in pASK-IBA3plus plasmids in order to generate $\mathrm{N}$ - and C-terminus streptavidin (Strep)-tagged proteins, respectively. Western blot analysis showed that cell extracts prepared from E. coli harboring pPID2 presented much lower expression levels of C-terminally tagged RH (data not shown). In contrast, a more efficient expression of RH genes was detected in $E$. coli if the enzyme was produced as N-terminus-tagged protein from plasmid pPD2. Nevertheless, both systems produced $\mathrm{RH}$ exclusively in inclusion bodies and neither variation in induction procedure, media, nor temperature yielded a soluble protein. The formation of inclusion bodies could be explained in this case by the inability of $E$. coli to properly coordinate the synthesis of the enzyme with the synthesis and integration of MoCo cofactor and $4 \mathrm{Fe}-4 \mathrm{~S}$ clusters.

\section{Complementation of T. aromatica AR1 $\Delta \mathrm{rhL}$ and T. aromatica AR1 $\Delta$ rhS with the Intact Resorcinol Hydroxylase Genes from the pSKM1 Plasmid}

Thauera aromatica AR1/Mu_21 (designated $\Delta r h L$ hereafter) and $T$. aromatica AR1/Mu_40 (designated $\Delta r h S$ hereafter) transconjugants [12] have transposons inserted in the genes coding for the large subunit and small subunit, respectively. Neither one was able to grow with resorcinol $(2 \mathrm{mM})$, but both grew with benzoate $(2 \mathrm{mM})$ in the presence of kanamycin. To examine whether plasmidborn alleles could complement $T$. aromatica AR1 RH mutants, $T$. aromatica AR1 $\Delta r h L$ and $T$. aromatica AR1 $\Delta r h S$ transconjugants were transformed with pSKM1 carrying the entire $r h L S$ locus plus the Strep-tag attached at the C-terminus of rhS. Thauera aromatica AR1 $\Delta r h L$ (pSKM1), and T. aromatica AR1 $\Delta r h S$ (pSKM1) transconjugants could grow with resorcinol as carbon and energy source under denitrifying conditions when cultivated in the presence of kanamycin and gentamicin. This indicated that both the mutated cosmid and the complementation plasmid could be maintained and that each transposon insertion mutation within the cosmid was complemented 

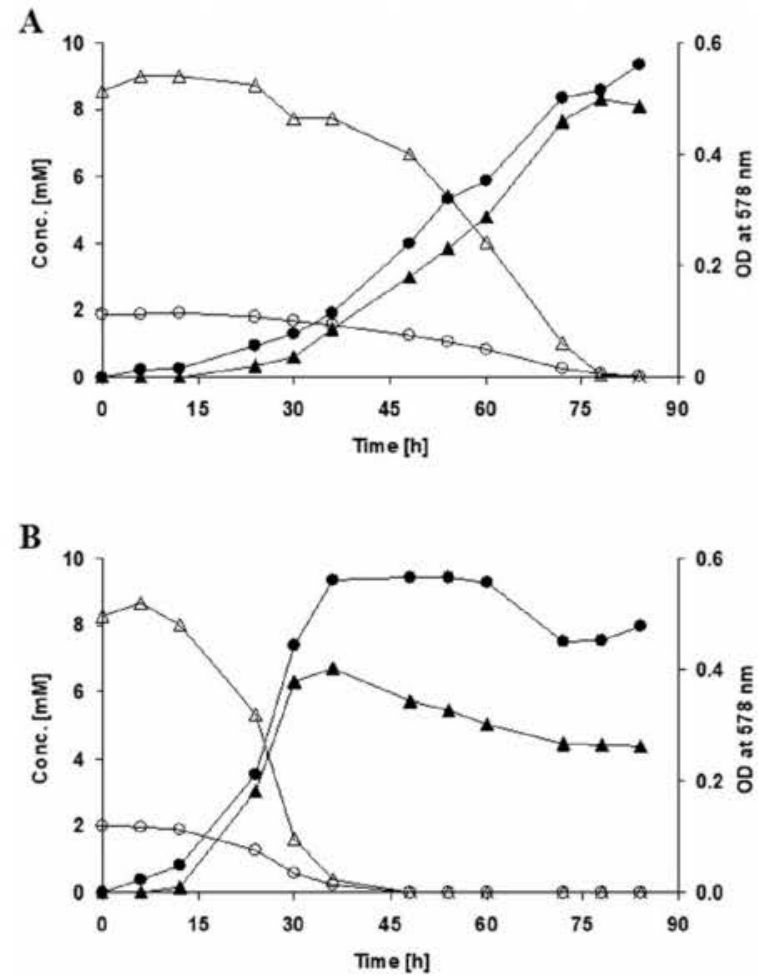

Fig. 2 Degradation of resorcinol by $A$. anaerobius grown in the absence (a) and in the presence (b) of $0.02 \mathrm{mM}$ molybdate. Resorcinol (open circles) is degraded with concomitant consumption of nitrate (open triangles), release of nitrite (filled triangles), and increase in OD at $578 \mathrm{~nm}$ (filled circles), measured in $1 \mathrm{~cm}$ cuvettes with a Hitachi 100-40 spectrophotometer. The results shown are mean values obtained from three independent experiments

by the plasmid-born wild-type allele. Growth and substrate depletion by $T$. aromatica AR1 $\Delta r h S$ (pSKM1) were compared to $T$. aromatica AR1 $\Delta r h S$ and wild-type transconjugant $T$. aromatica $\mathrm{AR} 1 / \mathrm{R}^{+}$, as negative and positive controls, respectively (Fig. 4a, b). Growth was coupled to resorcinol degradation and to simultaneous reduction of nitrate to nitrite; similar results were obtained with $T$. aromatica AR1 $\Delta r h L$ (pSKM1) (not shown). Figure 4c shows the RH expression level in the complemented $T$. aromatica AR1 $\Delta r h S$ (pSKM1) as detected in Western blot analysis of cell-free extracts prepared from cells grown with resorcinol. Furthermore, membrane and soluble fractions from both $T$. aromatica AR1 $\Delta r h L(\mathrm{pSKM} 1)$ and $\Delta r h S$ (pSKM1) were assayed for RH activity (Table 2 ). In the membrane fractions of both complemented mutants, the activities measured were comparable to those reported for the membranes of $T$. aromatica AR $1 / \mathrm{R}^{+}\left(80 \mathrm{mU} \mathrm{mg}^{-1}\right)$ [12]. The specific activities in the soluble fractions were very low, which is in agreement with low RH levels detected by immunoblot analysis in these fractions (not shown).

\section{Enrichment of Resorcinol Hydroxylase}

As RH could obviously functionally be expressed in $T$. aromatica AR1 $\Delta r h L$ and $T$. aromatica AR $1 \Delta r h S$ transformed with plasmid pSKM1, protein purification was attempted with this system (Table 2). In particular, $T$. aromatica AR1 $\Delta r h S$ (pSKM1) cells were used since they showed higher expression levels than those of $T$. aromatica AR1 $\Delta r h L$ (pSKM1). Despite the fact that some resorcinol hydroxylase activity could be measured in the soluble fractions of complemented $T$. aromatica transconjugants, no protein was purified by affinity chromatography. The fact that the protein did not bind to the affinity column suggests that the tag may not be accessible and could be buried inside the protein. In contrast, RH could be solubilized from membranes under strictly anoxic conditions with detergent. Most of the protein was released from the membranes during Triton X-100 treatment; however, from a starting activity of $70 \mathrm{mU} \mathrm{mg}^{-1}$ measured in the membrane fraction, only $11 \mathrm{mU} \mathrm{mg}^{-1}$ activity was recovered in the solubilisate, indicating about $80 \%$ loss of activity during this step. Nevertheless, solubilized RH bound to the column and was eluted mainly in fractions 3 and 4 (Fig. 5a, lanes E3 and E4). These two fractions were concentrated using commercially available Vivaspin centrifugation devices with $30 \mathrm{kDa}$ cut-off. As shown in Fig. 5b, the final preparation mainly contained two polypeptides with apparent molecular masses of 100 and $35 \mathrm{kDa}$, which are in agreement with the molecular masses predicted from the amino acid sequences of the large and small subunits of RH, respectively. Some further faint bands were observed as well, and the amounts of these polypeptides differed from one preparation to another. It is likely that $\mathrm{RH}$ had undergone some proteolytic degradation during purification. Similar cases of proteolysis were reported for other molybdenum-containing enzymes such as aldehyde oxidases [31-33]. The concentrated protein was colorless and inactive, suggesting that the cofactors were lost during purification and/or detergent treatment. One of the intriguing features of the A. anaerobius resorcinol hydroxylase is that even though activity was always detected in the membrane fraction, no membrane-binding elements were identified in either subunit. These findings lead us to speculate that the enzyme might contain a third subunit that functions as a membrane anchor. To verify this hypothesis, the complementation plasmid pSKM1 was engineered to produce a C-terminal strep-tagged small subunit which will allow a pull-down assay of a further subunit. Nonetheless, SDS-PAGE analysis of the purified resorcinol hydroxylase from the complemented resorcinol hydroxylase-deficient mutant showed only two major bands, indicating that $\mathrm{RH}$ consists of only two subunits or, if $\mathrm{RH}$ contains a third subunit, then it does not form a tight complex with RhLS. 
A

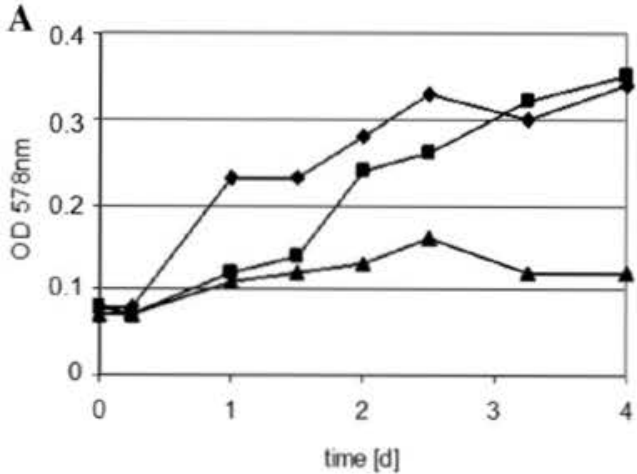

C

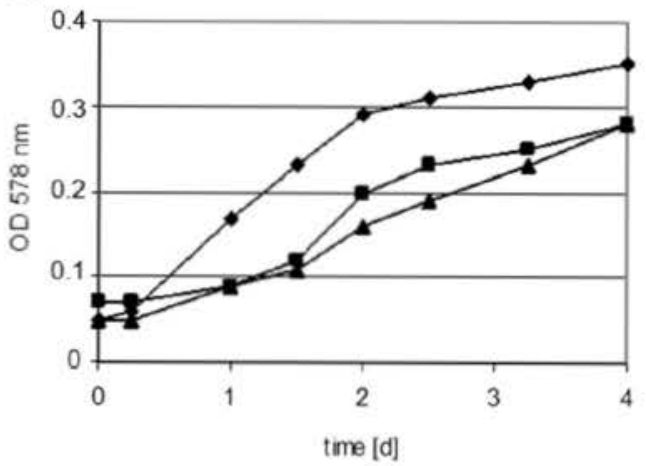

B

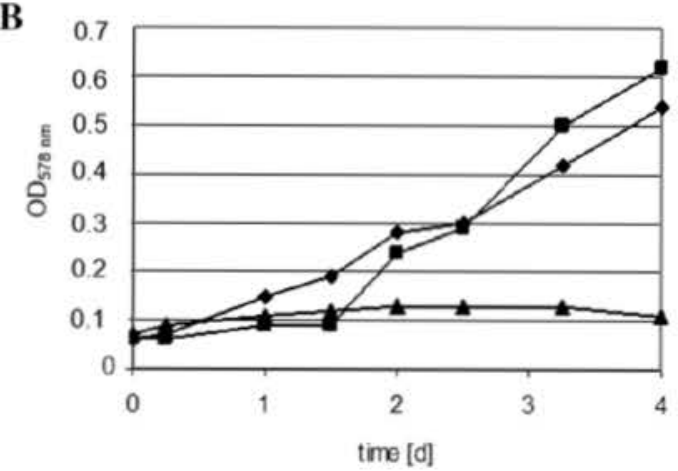

D

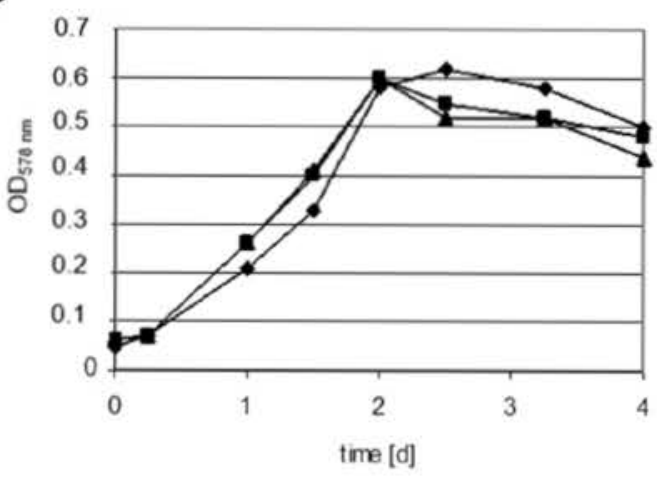

with $2 \mathrm{mM}$ resorcinol (a and b) or $5 \mathrm{mM}$ acetate (c and d) as carbon and energy source and $10 \mathrm{mM}$ nitrate (a and $\mathbf{c}$ ) or $10 \%$ nitrous oxide in the headspace (b and $\mathbf{d}$ ) as electron acceptor. The results show a representative experiment out of at least two independent biological replicates

dinucleotide site in the large subunit and two [4Fe-4S] centers in the small subunit. Apparently, this result excludes the presence of a third loosely membrane-bound subunit and raises the question of how the membrane association of RH is achieved. Although heterologous expression of a prokaryotic MoCo enzyme in E. coli is possible, e.g., with xanthine dehydrogenase of Rhodobacter capsulatus [37], all our attempts failed to purify resorcinol hydroxylase from $A$. anaerobius or from $E$. coli, expressing it both as $\mathrm{N}$ - or C-terminally tagged protein. Nevertheless, resorcinol hydroxylase was purified in the present study from a complemented RH-deficient mutant by affinity chromatography, as the complementation plasmid was engineered with a Strep-tag attached to the C-terminus of the small subunit. This enzyme was obtained inactive and in low amounts, most likely due to partial proteolytic degradation which was observed during purification and/ or due to loss of cofactors during protein solubilization and did not allow further characterization. Reconstitution of the native protein is difficult because MoCo cannot be reconstituted in vitro. The two putative iron-sulfur clusters 
A

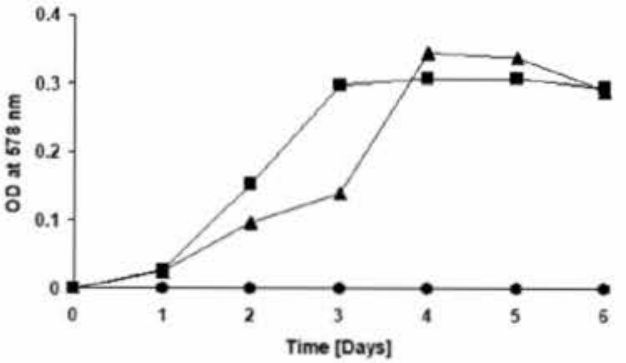

B

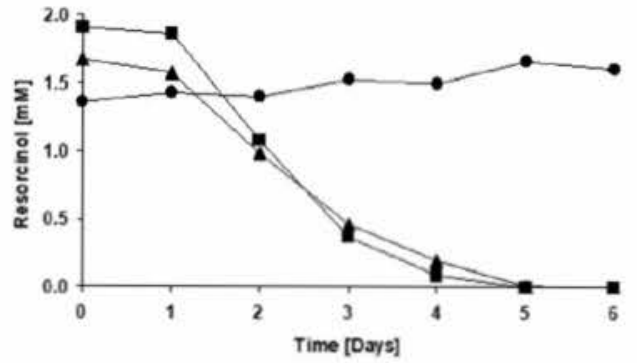

C

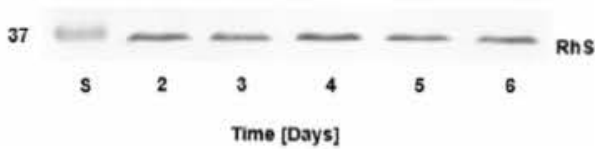

Fig. 4 Growth (a) and resorcinol degradation (b) by $T$. aromatica $\mathrm{AR} 1 / \mathrm{R}^{+}$(filled triangles), $T$. aromatica AR1 $\Delta r h S$ (filled circles) and $T$. anomatica ARI $\Delta r h S$ (pSKMI) (filled squares). Western blot analysis (c) of Strep-tagged C-terminus of $r h S$ in crude extracts of $T$. aromatica ARI $\Delta r h S$ (pSKMI) at the time intervals indicated. The marker protein $\mathrm{S}$ had a mass of $37 \mathrm{kDa}$. Results shown are mean val ues obtained from three independent experiments

Table 2 Expression and localization of resorcinol hydroxylase activities in $T$. aromatica ARI $\Delta r h L$ and $T$. aromatica ARI $\Delta r h S$ transconjugants harboring pSKMI plasmid

\begin{tabular}{llc}
\hline $\begin{array}{l}\text { T. ammatica AR } 1 \\
\text { transconjugants }\end{array}$ & Cell fraction & $\begin{array}{l}\text { Specific activity } \\
\left(\mathrm{mU} \mathrm{mg}^{-1} \text { protein) }\right.\end{array}$ \\
\hline$\Delta r h L$ (pSKM1) & Membranes & $81 \pm 9^{\mathrm{a}}$ \\
& Soluble & $5 \pm 2^{\mathrm{a}}$ \\
$\Delta r h S$ (pSKM1) & Membranes & $95 \pm 12^{\mathrm{b}}$ \\
& Soluble & $7 \pm 1^{\mathrm{b}}$ \\
\hline
\end{tabular}

"Mean \pm standard deviation, two determinations

${ }^{b}$ Mean \pm standard deviation, four determinations

predicted to be embedded in the small subunit of RH could be involved in electron flow or could play a role only in maintaining proper protein folding.
A

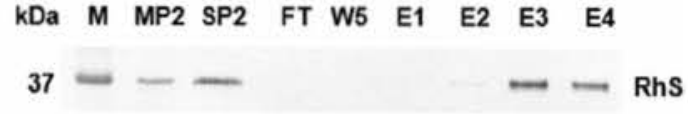

B

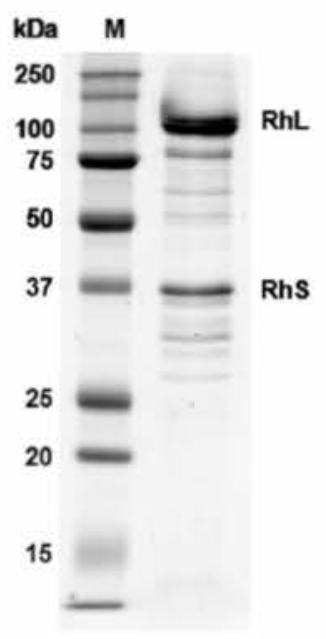

Fig. 5 Purification of RH. a Western blot analysis of purified RhSL from $T$. aromatica ARl $\Delta r h S$ (pSKM1) expressing a C-terminal Strep-tagged $r h S L$. Lane M, molecular mass marker; lane MP2, membrane fraction containing Strep-tagged rhSL that remained in the membrane fraction after solubilization with Triton X-100; lane SP2, solubilized membranes with Triton X-100; lane FT, flow through: lane W5, last washing before elution of RhSL with desthiobiotin; E1-4 elution fractions. Molecular mass of standard protein $(M)$ and the position of RhS are indicated. b SDS-PAGE analysis of RH purified from T. aromatica ARl $\Delta r h S$ (pSKMI). Molecular masses of standard proteins $(\mathrm{M})$ and the positions of $\mathrm{RhS}$ and $\mathrm{RhL}$ are indicated

Author Contributions All authors developed the concept of this study. $\mathrm{PD}$ and $\mathrm{JH}$ carried out the experiments and wrote a first draft. BS and $\mathrm{BP}$ wrote the final version of the manuscript on which all authors agreed.

\section{Compliance with Ethical Standards}

Conflict of interest The authors declare that they hhave no conflicts of interests.

\section{References}

1. Harwood CS, Parales RE (1996) The beta-ketoadipate pathway and the biology of self-identity. Annu Rev Microbiol 50:553-590. https://doi.org/10.1146/annurev.micro.50.1.553

2. Fuchs G, Boll M, Heider J (2011) Microbial degradation of aromatic compounds-from one strategy to four. Nat Rev Microbiol 9:803-816. https://doi.org/10.1038/nrmicro2652 
3. Carmona M, Zamarro MT, Blázquez B, Durante-Rodríguez G, Juárez JF, Valderrama JA, Barragán MJ, García JL, Díaz E (2009) Anaerobic catabolism of aromatic compounds: a genetic and genomic view. Microbiol Mol Biol Rev 73(1):71-133, https ://doi.org/10.1128/MMBR.00021-08

4. Boll M, Fuchs G, Heider J (2002) Anaerobic oxidation of aromatic compounds and hydrocarbons. Curr Opin Chem Biol 6:604-611. https://doi.org/10.1016/s1367-5931(02)00375-7

5. Schink B, Philipp B, Müller J (2000) Anaerobic degradation of phenolic compounds. Naturwissenschaften 87:12-23. https://doi. org/10.1007/s001 140050002

6. Philipp B, Schink B (1998) Evidence of two oxidative reaction steps initiating anaerobic degradation of resorcinol (1,3-dihydroxybenzene) by the denitrifying bacterium Azoarcus anaerobius. J Bacteriol 180:3644-3649

7. Gallus C, Schink B (1998) Anaerobic degradation of $\alpha$-resorcylate by Thauera aromatica strain AR-1 proceeds via oxidation and decarboxylation to hydroxyhydroquinone. Arch Microbiol 169:333-338. https://doi.org/10.1007/s002030050579

8. Philipp B, Schink B (2000) Two distinct pathways for anaerobic degradation of aromatic compounds in the denitrifying bacterium Thauera aromatica strain AR-1. Arch Microbiol 173:91-96. https ://doi.org/10.1007/s002039900112

9. Pacheco-Sánchez D, Rama-Garda R, Marín P, Martirani-Von Abercron SM, Marqués S (2019) Occurrence and diversity of the oxidative hydroxyhydroquinone pathway for the anaerobic degradation of aromatic compounds in nitrate-reducing bacteria. Environ Microbiol Rep 11:525-537. https://doi. org/10.1111/1758-2229.12752

10. Pacheco-Sánchez D, Molina-Fuentes Á, Marín P, MedinaBellver JI, González-López O, Marqués S (2017) The Azoarcus anaerobius 1,3-dihydroxybenzene (resorcinol) anaerobic degradation pathway is controlled by the coordinated activity of two enhancer-binding proteins. Appl Environ Microbiol, https://doi. org/10.1128/AEM.03042-16

11. Pacheco-Sánchez D, Molina-Fuentes Á, Marín P, Díaz-Romero A, Marqués S (2019) DbdR, a new member of the LysR family of transcriptional regulators, coordinately controls four promoters in the Thauera aromatica AR-1 3,5-dihydroxybenzoate anaerobic degradation pathway. Appl Environ Microbiol. https://doi. org/10.1128/AEM.02295-18

12. Darley PI, Hellstern JA, Medina-Bellver JI, Marques S, Schink B, Philipp B (2007) Heterologous expression and identification of the genes involved in anaerobic degradation of 1,3-dihydroxybenzene (resorcinol) in Azoarcus anaerobius. J Bacteriol 189:3824-3833. https://doi.org/10.1128/JB.01729-06

13. Molina-Fuentes Á, Pacheco D, Marín P, Philipp B, Schink B, Marqués $\mathrm{S}$ (2015) Identification of the gene cluster for the anaerobic degradation of 3,5-dihydroxybenzoate ( $\alpha$-resorcylate) in Thauera aromatica Strain AR-1. Appl Environ Microbiol 81:7201-7214

14. Hille R, Retey J, Bartlewski-Hof U, Reichenbecher W, Schink B (1999) Mechanistic aspects of molybdenum-containing enzymes. FEMS Microbiol Rev 22:489-501. https://doi. org/10.1111/j.1574-6976.1998.tb00383.x

15. Messerschmidt A, Niessen H, Abt D, Einsle O, Schink B, Kroneck PM (2004) Crystal structure of pyrogallol-phloroglucinol transhydroxylase, an Mo enzyme capable of intermolecular hydroxyl transfer between phenols. Proc Natl Acad Sci USA 101:1157111576. https://doi.org/10.1073/pnas.0404378101

16. Sambrook J, Russell DW (1989) Molecular cloning. A laboratory manual. Cold Spring Harbor Laboratory Press, Cold Spring Harbor

17. Bradford MM (1976) A rapid and sensitive method for the quantitation of microgram quantities of protein utilizing the principle of protein dye binding. Anal Biochem 72:248-254
18. Laemmli UK (1970) Cleavage of the structural proteins during the assembly of the head of the bacteriophage T4. Nature 227:680685. https://doi.org/10.1038/227680a0

19. Schindelin H, Kisker C, Hilton J, Rajagopalan KV, Rees DC (1996) Crystal structure of DMSO reductase: redox-linked changes in molybdopterin coordination. Science 272:1615-1621. https://doi.org/10.1126/science.272.5268.1615

20. Schneider F, Lowe J, Huber R, Schindelin H, Kisker C, Knablein J (1996) Crystal structure of dimethyl sulfoxide reductase from Rhodobacter capsulatus at 1.88 A resolution. J Mol Biol 263:53-69. https://doi.org/10.1006/jmbi.1996.0555

21. Boyington JC, Gladyshev VN, Khangulov SV, Stadtman TC, Sun PD (1997) Crystal structure of formate dehydrogenase H: catalysis involving Mo, molybdopterin, selenocysteine, and an $\mathrm{Fe}_{4} \mathrm{~S}_{4}$ cluster. Science 275:1305-1308. https://doi.org/10.1126/scien ce. 275.5304 .1305

22. Jormakka M, Tornroth S, Byrne B, Iwata S (2002) Molecular basis of proton motive force generation: structure of formate dehydrogenase-N. Science 295:1863, https://doi.org/10.1126/science.10681 86

23. Dias JM, Than ME, Humm A, Huber R, Bourenkov GP, Bartunik HD, Bursakov S, Calvete J, Caldeira J, Carneiro C, Moura JJ, Moura I, Romão MJ (1999) Crystal structure of the first dissimilatory nitrate reductase at $1.9 \mathrm{~A}$ solved by MAD methods. Structure 7:65-79. https://doi.org/10.1016/s0969-2126(99)80010-0

24. Menendez C, Otto A, Igloi G, Nick P, Brandsch R, Schubach B, Bottcher B, Brandsch R (1997) Molybdate-uptake genes and molybdopterin-biosynthesis genes on a bacterial plasmid - characterization of MoeA as a filament-forming protein with adenosinetriphosphatase activity. Eur J Biochem 250:524-531. https://doi. org/10.1111/j.1432-1033.1997.0524a.x

25. Kisker C, Schindelin H, Rees DC (1997) Molybdenum-cofactor-containing enzymes: structure and mechanism. Annu Rev Biochem 66:233-267. https://doi.org/10.1146/annurev.bioch em.66.1.233

26. Zumft WG (1997) Cell biology and molecular basis of denitrification. Microbiol Mol Biol Rev 61:533-616

27. Blaschke M, Kretzer A, Schäfer C, Nagel M, Andreesen JR (1991) Molybdenum-dependent degradation of quinoline by Pseudomonas putida Chin IK and other aerobic bacteria. Arch Microbiol 155:164-169

28. Johnson JL (1988) Molybdenum. Methods Enzymol 158:371-382

29. Coughlan MP, Johnson JL, Rajagopalan KV (1980) Mechanism of inactivation of molybdenum enzymes by cyanide. J Biol Chem 255:2694-2699

30. Voet D, Voet JG (1994) Biochemie, 1st edn. VCH Verlagsgesellschaft mbH, Weinheim

31. Koshiba T, Saito E, Ono N, Yamamoto N, Sato M (1996) Purification and properties of flavin- and molybdenum-containing aldehyde oxidase from coleoptiles of maize. Plant Physiol 110:781789. https://doi.org/10.1104/pp.110.3.781

32. Stell JG, Warne AJ, Lee-Woolley C (1989) Purification of rabbit liver aldehyde oxidase by affinity chromatography on benzamidine sepharose 6B. J Chromatogr 475:363-372. https://doi. org/10.1016/s0021-9673(01)89690-4

33. Yoshihara S, Tatsumi K (1985) Guinea pig liver aldehyde oxidase as a sulfoxide reductase: its purification and characterization. Arch Biochem Biophys 242:213-224. https://doi.org/10.1016/00039861(85)90495-3

34. Heider J, Szaleniec M, Sünwoldt K, Boll M (2016) Ethylbenzene dehydrogenase and related molybdenum enzymes involved in oxygen-independent alkyl chain hydroxylation. J Mol Microbiol Biotechnol 26:45-62. https://doi.org/10.1159/000441357

35. Dermer J, Fuchs G (2012) Molybdoenzyme that catalyzes the anaerobic hydroxylation of a tertiary carbon atom in the side 
chain of cholesterol. J Biol Chem 287:36905-36916. https://doi. org/10.1074/jbc.M112.407304

36. Philipp B, Schink B (2012) Different strategies in anaerobic biodegradation of aromatic compounds: nitrate reducers versus strict anaerobes. Environ Microbiol Rep 4:469-478. https://doi.org/10 $.1111 / \mathrm{j} .1758-2229.2011 .00304 . x \hat{A}$

37. Hall J, Reschke S, Cao H, Leimkühler S, Hille R (2014) The reductive half-reaction of xanthine dehydrogenase from Rhodobacter capsulatus: the role of Glu232 in catalysis. J Biol Chem 289:32121-32130. https://doi.org/10.1074/jbc.M1 14.603456

38. Springer N, Ludwig W, Philipp B, Schink B (1998) Azoarcus anaerobius sp. nov., a resorcinol-degrading, strictly anaerobic, denitrifying bacterium. Int J Syst Bacteriol 48:953-956. https:// doi.org/10.1099/00207713-48-3-953

39. Herrero M, de Lorenzo V, Timmis KN (1990) Transposon vectors containing non-antibiotic resistance selection markers for cloning and stable chromosomal insertion of foreign genes in gram-negative bacteria. J Bacteriol 172:6557-6567. https://doi. org/10.1128/jb.172.11.6557-6567.1990

40. Kovach ME, Elzer PH, Hill DS, Robertson GT, Farris MA, Roop RM, Peterson KM (1995) Four new derivatives of the broad-host-range cloning vector pBBR IMCS, carrying different antibiotic-resistance cassettes. Gene 166:175-176. https://doi. org/10.1016/0378-1119(95)00584-1

41. Li KB (2003) ClustalW-MPI: ClustalW analysis using distributed and parallel computing. Bioinformatics 19:1585-1586. https://doi. org/10.1093/bioinformatics/btg 192 